\title{
Social Presence in Massive Open Online Courses
}
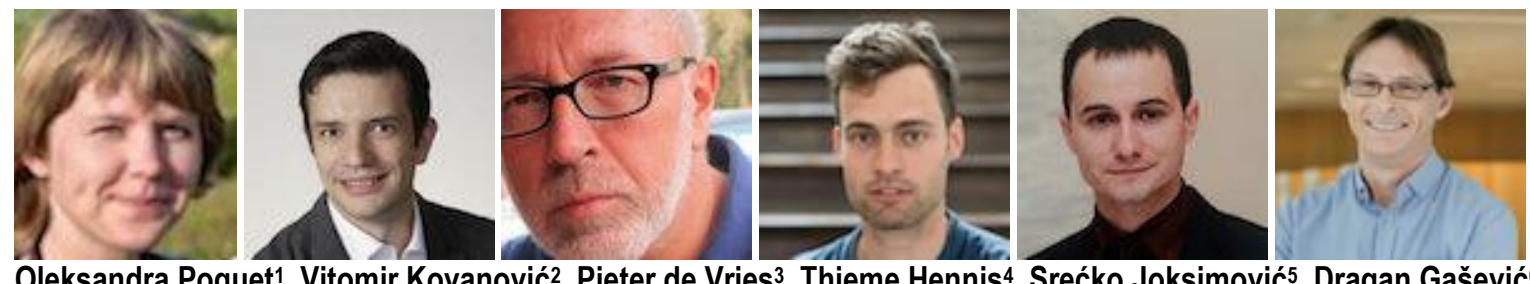

Oleksandra Poquet ${ }^{1}$, Vitomir Kovanović2 ${ }^{2}$, Pieter de Vries ${ }^{3}$, Thieme Hennis ${ }^{4}$, Srećko Joksimovićs ${ }^{5}$, Dragan Gašević ${ }^{6}$, and Shane Dawson ${ }^{7}$

${ }^{1}$ Institute for Application of Learning Science and Educational Technology, National University of Singapore, ${ }^{2}$ Teaching Innovation Unit and School of Education, University of South Australia, ${ }^{3}$ Delft University of Technology, ${ }^{4}$ BorderLabs, ${ }^{5}$ Teaching Innovation Unit and School of Education, University of South Australia, ${ }^{6}$ Faculty of Education and Faculty of Information Technology, Monash University, ${ }^{7}$ Teaching Innovation Unit, University of South Australia

\begin{abstract}
The capacity to foster interpersonal interactions in massive open online courses (MOOCs) has frequently been contested, particularly when learner interactions are limited to MOOC forums. The establishment of social presence-a perceived sense of somebody being present and "real"-is among the strategies to tackle the challenges of online learning and could be applied in MOOCs. Thus far, social presence in MOOCs has been under-researched. Studies that previously examined social presence in MOOCs did not account for the peculiar nature of open online learning. In contrast to the existing work, this study seeks to understand how learners perceive social presence, and the different nuances of social presence in diverse MOOC populations. In particular, we compare perceptions of social presence across the groups of learners with different patterns of forum participation in three edX MOOCs. The findings reveal substantial differences in how learners with varying forum activity perceive social presence. Perceptions of social presence also differed in courses with the varying volume of forum interaction and duration. Finally, learners with sustained forum activity generally reported higher social presence scores that included low affectivity and strong group cohesion perceptions. With this in mind, this study is significant because of the insights into brings to the current body of knowledge around social presence in MOOCs. The study's findings also raise questions about the effectiveness of transferring existing socio-constructivist constructs into the MOOC contexts.
\end{abstract}

Keywords: social presence, MOOCs, forum participation 


\section{Introduction}

With the steady expansion of online education, the numbers of students enrolling in scaled open courses (e.g., massive open online courses [MOOCs]) worldwide have reached beyond millions (Shah, 2015). Such an explosion in student numbers obviously has implications for the design of education at scale and its capacity to promote and facilitate peer interactions. The dynamics of MOOCs creates a challenging environment for stimulating and fostering peer interactions (Daniel, 2012). This is due to the unprecedented volume of communication, often at a scale several orders of magnitude larger than in formal courses. Open participation in MOOCs further contributes to the difficulty of peer interactions. As the learners are not obliged to engage in social activities or complete the assigned assessment in the course, they exhibit varying patterns of use when it comes to the course resources (Bergner, Kerr, \& Pritchard, 2015; Eynon, Gillani, Hjorth, \& Yasseri, 2014).

Limited capacity to foster interpersonal interactions challenges the quality of online educational experience in MOOCs. Learning science and contemporary educational research demonstrates that engagement in peer interactions can bring numerous cognitive and socioemotional benefits. For instance, peer interactions may enhance a student's understanding by allowing the student to verbalise a problem, seek or receive help, or coconstructing a solution (Bransford, Brown, \& Cocking, 2000; Dillenbourg, Baker, Blaye, \& O'Malley, 1996; Webb, 1982). Perceptions of belonging to a group and the development of trust that are fostered through peer interactions also impact learning more indirectly insofar as they influence student motivation and satisfaction (Arbaugh \& Benbunan-Fich, 2006; Johnson, 1981; Thomas, 2000). The potential of experiencing these kinds of cognitive and emotional learning supports in MOOCs remains questionable.

Within formal online education, social presence is one of the constructs that helps examine the link between peer interactions and student learning. In small formal online courses, social presence has been closely associated with the development of interpersonal interactions and the garnering of a learner community over time (Gunawardena, 1995; Rovai, 2002; Rovai \& Barnum, 2007; Swan, 2002, 2004). It has further been deemed important for maintaining a high degree of peer interaction (Kreijns, Kirschner, Jochems, \& Buuren, 2011) and even regarded as the vehicle driving social learning (Tu \& McIsaac, 2002). Research has also demonstrated the positive impact social presence has on students in terms of retention and academic performance (Boston et al., 2009; Liu, Gomez, \& Yen, 2009), and a recent meta-analysis revealed a strong correlation between social presence and perceived learning (Richardson, Maeda, Lv, \& Caskurlu, 2017).

This study adopts a social presence lens to examine the effects of interpersonal interactions on learner perceptions in MOOCs. Social presence in MOOCs has been largely underexplored. Kop and Fournier (2013) suggested that the development of social presence at scale could counter anonymity in MOOCs, but their call for examining social presence in MOOCs has barely been addressed. The findings in the few existing studies appear aligned with those derived from formal online education. For instance, Cheung (2014), examined the forum discourse to derive social presence indicators and found that those learners exhibiting higher social presence tend to receive a higher final grade. Kilgore and Lowenthal (2015) surveyed participant perceptions of social presence in their MOOC and demonstrated that social presence can be established at scale; they argued that it should, therefore, be facilitated within the massive cohorts.

The current study draws attention to a limitation that permeates through the existing research of social presence in MOOCs. We argue that existing investigations of social presence are methodologically unsuited to describe MOOC contexts. MOOC forums garner a context for interaction that is dissimilar to that of more formal education courses. For example, unlike individuals in formal online courses, MOOC learners are highly 
diverse in the way in which they participate in forums-that is, all learners do not start the course on the same day, nor do they all follow the course until the end (Yang, Sinha, Adamson, \& Rosé, 2013). Without a requirement to commit to studying, some MOOC learners use forums to find what they need quickly; others join at random times throughout the course; and some learners consider the forum to be an essential part of their online experience (Eynon, Gillani, Hjorth, \& Yasseri, 2014). The construct of social presence in formal online courses, however, presupposes continuous appearance of the same group of students throughout the course, as well as the continuity of interactions among them. This continuity assumption is also evident in the scholarly descriptions of the elements of social presence (Garrison \& Akyol, 2013).

The existing studies of social presence in MOOCs made no methodological adjustments to account for these important differences between formal online courses and MOOCs. Hence, the insights derived from these studies are ill-suited to the specificities of the MOOC environment, and their findings are difficult to interpret. The aim of the current study is to understand how to evaluate social presence in MOOCs so that it captures the complexity of MOOC environments. To do so, our study analyses social presence in MOOC environments in two ways: analysis is conducted first on data from the entire respondent sample, and second, on that from different subpopulations of posters in MOOC forums. The data used in the study was collected from three MOOCs delivered via edX platform in 2014. The research design is exploratory, as log data of forum posting activity is combined with self-reported data. Drawing on our findings, we argue that accounting for the differences in how learners use the forums allows a more nuanced understanding of social presence in MOOCs, and that this can offer instructors a more accurate evaluation of how well they facilitate social presence. More importantly, our analysis of social presence in learner subpopulations shows a somewhat different picture of social presence than that which is found across the entire group of respondents. These discrepant results raise a critical question about how the constructs developed within formal online education should be transferred and adapted as new digital environments continue to emerge.

\section{Literature Review}

\section{Social Presence}

Social presence can be intuitively described as "feeling as if someone is socially present in one's life although they are not physically in the same space” (Kim, Song, \& Luo, 2016, p. 674). However, as highlighted through a recent meta-analysis, definitions and operationalisations of social presence are greatly varied (Richardson et al., 2017), including meanings such as "social interaction, immediacy, intimacy, emotion, and/or connectedness" (Lowenthal, 2009, p. 4). In this section, we briefly review the historical development of the concept to distinguish some of the critical differences in definitional foci. We then focus on the operationalisation of social presence within the Community of Inquiry (CoI) model (Garrison, Anderson, \& Archer, 1999), as this study used the CoI survey instrument to collect participant perceptions of social presence. Finally, recent developments in social presence concept are outlined.

Definitions of social presence. Distance education researchers originally became interested in social presence because of the perceived lack of communication cues in educational technologies. Technology that afforded intimacy and immediacy in communication was seen as instrumental in shortening the psychological distance between two speakers (Swan, 2003). Short, Williams, and Christie (1976) changed the essence of social presence definition from the affordances of the technological medium to learner perceptions 
to the level of "salience" emerging from the interaction between two or more participants. Subsequent social presence theorists built upon the conceptual premise put forward by Short et al. (1976). Gunawardena (1995) adopted Short et al.'s understanding of social presence, and the concept was further extended by Rourke, Anderson, Garrison, and Archer (2001) to include individual's ability to project oneself emotionally and socially. Both Rourke et al. (2001) and Picciano (2002) added new layer of meaning to the construct of presence, characterising it as having socioemotional quality through connectedness and the sense of belonging. Lowenthal (2009) described various social presence definitions as being positioned on a continuum: social presence defined as perception of another person being real situated at the one end on the spectrum, and social presence defined as perceptions of another person also characterised with a certain socio-emotional quality (as well as one's ability to project oneself emotionally) located at the other.

Operationalisation of social presence within the CoI model. Operationalisations of social presence vary as much as their corresponding definitions (see Kreijns, Van Acker, Vermeulen, \& Van Buuren, 2014; Richardson et al., 2017). Among the instruments most commonly used to capture social presence is a component of the CoI model (Garrison et al., 1999; Na Ubon \& Kimble, 2004; Tu, 2002; Weaver \& Albion, 2005). Within the CoI model, social presence is linked to the emergence of one-to-one interpersonal relationships that evolve into a learning climate that is supportive of open, critical disagreement (Garrison \& Akyol, 2013). Specifically, social presence within the CoI model is defined as "the ability of participants to identify with the community (e.g., course of study), communicate purposefully in a trusting environment, and develop interpersonal relationships by way of projecting their individual personalities" (Garrison, 2009). Garrison, Cleveland-Innes, and Fung (2010) validated the survey instrument and confirmed that social presence serves as a mediator between teaching presence and cognitive presence, indirectly influencing student learning. Gutiérrez-Santiuste, Rodríguez-Sabiote, and Gallego-Arrufat (2015) similarly showed strong correlations between social presence and cognitive presence.

CoI operationalisations of social presence have been challenged by Kreijns et al. (2014). This challenge has been further developed by Weidlich and Basianens (2017). Their critique is largely in line with the argument that definitions of social presence often blur the line between "social presence and psychological or behavioural effects/causes/correlates of social presence" (Biocca et al., 2003, cited in Kim et al., 2016). Detailed discussion of these conceptualisations is beyond the scope of this paper; for a short discussion of how these critiques relate to this study's findings, see Discussion section.

Considering the validity of the CoI model and measures and its extensive use among online education practitioners, this study applied the CoI questionnaire to collect students' perceptions of social presence in MOOC contexts. We opted to use the CoI instrument as it has been extensively validated across different learning settings (Arbaugh et al., 2008; Carlon et al., 2012; Díaz, Swan, Ice, \& Kupczynski, 2010), including a recent validation of the $\mathrm{CoI}$ instrument within MOOC settings (Kovanovic et al., 2017). The social presence aspect of the CoI survey instrument inquires about students' perceptions of three components of social presence: (1) group cohesion; (2) open communication; and (3) affective expression.

\section{Social Presence in a MOOC Context}

Although the importance of social presence in online learning settings has been well noted (Joksimović, Gašević, Kovanović, Riecke, \& Hatala, 2015; Picciano, 2002; Rovai, 2002; Tao, 2009), an overwhelming majority of research in the area of social presence is situated within the formal education context. Only a few studies examine learner perceptions of social presence in MOOCs. Kilgore and Lowenthal (2015), for example, 
found that MOOC participants "were able to experience social presence first hand and that social presence can be established in large online courses" (p. 398). In contrast, Damm (2016) demonstrated that most of their MOOC learners either disagreed that social presence was established across the different aspects of the MOOC, or marked social presence as a nonapplicable aspect for their course evaluation.

A more recent examination of the CoI survey instrument in MOOC settings was conducted by Kovanović et al. (2017). The authors demonstrated that some of the sub-constructs within the CoI model were more prominent than expected in a formal setting and in a MOOC setting can be viewed as standalone constructs. In particular, when it comes to social presence, affective expression had different dynamics than the rest of the social presence constructs (as indicated by a factor analysis). This particular finding raises questions about how social presence is formed to begin with. In models of formal online education, affective expression has been hypothesized to have a relationship with another subconstruct: group cohesion. Akyol, Garrison, and Ozden (2009) showed that as affective expression levels decrease over time within a course, group cohesion levels tend to increase. Similarly, later models (Kreijns et al., 2014; Weidlich \& Bastiaens, 2017) theorise a causal relationship between impression formation (similar to affective expression) and social space (similar to group cohesion). The finding by Kovanović et al. (2017) that affective expression could be viewed as a factor separate from social presence suggests that in MOOCs-in contrast to formal, bounded groups of learners-the relationship between the formation of one-to-one impressions and group development may differ.

Despite the clear differences between the MOOC context and formal online education, as well as possible differences in how social presence may unfold at scale, research surrounding social presence in MOOCs has not addressed these methodologically or in any conceptual manner. Hence, in the studies that focused on social presence in MOOCs (Appiah-Kubi \& Rowland, 2016; Cheung, 2014; Kilgore \& Lowenthal, 2015), all forum users were treated as if they all started on the same date and interacted continuously. Such an approach assumes that the entire population of learners surveyed was appropriately described by a continuity of interactions, as is ideally the case in a formal online cohort. However, in a MOOC setting such an assumption does not hold; hence, the learner population being studied is incompatible with the instrument applied.

To address the discrepancies between the context used to derive the concept of social presence and the MOOC context, this study evaluates social presence perceptions across the group of forum users with a differing commitment to social activity. Empirical research of MOOC forums has offered substantial evidence that there are clear participation patterns in MOOC forums. Existing classifications of MOOC engagement patterns in forums reveal that a small group of learners engage persistently with the forums, which contrasts with the intermittent participation of a large number of learners who engaging and disengaging randomly (Coffrin, Corrin, de Barba, \& Kennedy, 2014; Ferguson \& Clow, 2015; Hecking, Chounta, \& Hoppe, 2016; Kizilcec, Piech, \& Schneider, 2013; Milligan, Littlejohn, \& Margaryan, 2013; Poquet, 2017; Poquet, Dowell, Brooks, \& Dawson, 2018; Rodrigues et al., 2016; Boroujeni, Hecking, Hoppe, \& Dillenbourg, 2017). Moreover, viewing without posting has also been found to be the activity most characteristic of MOOC forum users (Bergner et al., 2015). Adjusting the CoI instrument to observe social presence across these different groups of learners would allow some alignment with the dynamics of MOOC forums.

\section{Research Question}

In line with our argument about the mismatch between a socio-constructivist social presence construct and an open MOOC context, the present study was designed to address two research questions: 
RQ1. What does social presence in MOOCs look like when evaluated across the entire group of forum users through the social presence aspect of the CoI model?

RQ2. What is the association between student perceptions of social presence and their levels of participation in MOOC discussion forums, and does this perception differ across the groups of learners with varying participation patterns?

By addressing these questions, this study demonstrates whether or not different ways of evaluating social presence bring consistent insights. Answering the second research question will help establish the relationship between student's self-reported perceptions of social presence and the log data derived from their posting activity.

\section{Method}

Student perceptions of social presence were collected through the CoI questionnaire (Arbaugh et al., 2008). To better understand the association between levels of participation in MOOC forums and student perceptions of social presence, we compared self-reported levels of social presence between the groups with varying levels of forum activity: forum participants who consistently posted on the forums, those who posted occasionally, and those who did not post. The design of the study was exploratory, as we wanted to understand if the reported social presence would differ across these three groups, as well as if it would differ from the averages reported on the entire sample of respondents.

The survey was implemented in three edX MOOC run by the Delft University of Technology in 2014: (1) Delft Design Approach (DDA); (2) Introduction to Functional Programming (FP); and (3) Creative Problem Solving and Decision Making (TPM). The MOOCs differed in subject, duration, and pedagogical design in relation to forum activity. To account for course instructional, disciplinary, and contextual specificity, the analysis was done for each course separately. All students were invited to participate in a post-course survey administered in the final weeks of each course. In all three courses, no specially designed learning interventions were incorporated to facilitate interpersonal interactions.

\section{Data Description and User Groups}

To account for the varying frequency and quality of participant forum use, survey respondents were divided into three groups based on the regularity of their forum activity rather than the volume of such activity. Poquet (2017) demonstrated that learners who participate regularly co-occur with one another over the course duration-that is, individuals posting with certain regularity are also defined by the continuity of interactions, much like cohorts inside formal online courses.

The first group, regular posters, comprised all MOOC learners making forum posts for three weeks or more (Table 3). If, for example, a learner made one post in week 1 , three posts in week 5 , and twenty posts in week ten, this person would be considered a regular poster. The division into regular and occasional posters was based both on data exploration and latent class analysis (for the method, please see Poquet et al., 2018; model outputs not reported here). Latent class analysis of this dataset replicated the findings of Poquet et al. (2018) that learners who post in any three weeks of a course are more likely to use the forums longer, whereas learners who post in any two weeks are more likely to use the forums for two weeks only. 
The second group of participants, occasional posters, included all students who had posted in the discussions at any time for (any) one or two weeks of the course.

Finally, course participants who did not post in the discussions but filled out the questionnaire were grouped as non-posters.

Table 1

Data Description: Summary of the Sample

\begin{tabular}{|c|c|c|c|c|c|c|c|c|c|}
\hline Course & $\begin{array}{l}\text { Enrolled } \\
\text { students }\end{array}$ & $\begin{array}{l}\text { Certified } \\
\text { students }\end{array}$ & $\begin{array}{r}\text { Course } \\
\text { duration } \\
\text { (weeks) }\end{array}$ & $\begin{array}{r}\text { Regular } \\
\text { forum } \\
\text { posters }\end{array}$ & $\begin{array}{r}\text { Occasional } \\
\text { forum } \\
\text { posters }\end{array}$ & $\begin{array}{r}\text { Forum } \\
\text { contributors } \\
\text { (total) }\end{array}$ & $\begin{array}{r}\text { Survey } \\
\text { responses } \\
\text { (total) }\end{array}$ & $\begin{array}{r}\text { Regularly- } \\
\text { posting } \\
\text { respondents }\end{array}$ & $\begin{array}{r}\text { Occasionally- } \\
\text { posting } \\
\text { respondents }\end{array}$ \\
\hline DDA & 13,503 & 136 & 10 & 62 & 442 & 504 & 78 & 18 & 29 \\
\hline FP & 38,029 & 1,968 & 8 & 177 & 850 & 1,027 & 1,066 & 117 & 243 \\
\hline TPM & 32,424 & 1,396 & 5 & 72 & 998 & 1,070 & 511 & 27 & 137 \\
\hline
\end{tabular}

Course 1: Delft Design Approach. DelftX DDA691X (Delft Design Approach, or DDA) was delivered by the Faculty for Industrial and Product Design. The 10-week course had 13,503 registered participants, with 136 course certificates awarded. The course employed interactive tasks, and learners were encouraged to discuss these on the forum. Peer assessment was a part of the course design. Student forum activity in the course decreased from 703 contributions in the first week to 237 in week 2 (see Table 2, below).

Course activity decreased in volume, with a small group of 62 regular posters repeatedly contributing to the forum for three or more weeks of the course (see Table 1, above). At the end of the course, a total of 78 respondents completed the CoI surveys, with 18 of them being regular contributors, 29 occasional contributors, and 37 non-posters. From those who completed the survey, more than half were completers with certificates; the remaining respondents also included learners who started the course but did not complete it, and those who audited parts of the course.

Course 2: Introduction to Functional Programming. The second course, DelftX FP101X (Introduction to Functional Programming, or FP) was delivered by the Faculty of Computer Science. The eightweek course was based on the foundations of functional programming using the Haskell programming language. The course assessed learner knowledge through quizzes and had no special provisions for the forum activity, except that the course instructor and several teacher assistants actively communicated with the students on the forum. The course enrolled 38,029 students and certified 1,968 of them.

The volume of forum activity decreased from week 1 to week 2, but the decrease was not as drastic as that observed in DDA. The volume of interactions fluctuated between 700 and 900 interactions weekly, produced by some 160 to 200 students (see Table 2, below). Thirteen participants interacted with others every week of the course, and the group of regular contributors comprised 177 participants (see Table 1, above). 
CoI surveys at the end of the course were completed by 1,066 individuals, 117 of which were regular contributors, 243 occasional contributors, and 706 non-posters. Similar to the DDA sample, the respondents mostly represented the certified completers, but also included people auditing the course and students who disengaged at some point during the course.

Table 2

The Number of Posts and Posters in Every Subsequent Week of the Course

\begin{tabular}{|c|c|c|c|c|c|c|c|c|c|c|}
\hline & $\begin{array}{r}\text { Week } \\
1\end{array}$ & $\begin{array}{r}\text { Week } \\
2\end{array}$ & $\begin{array}{r}\text { Week } \\
3\end{array}$ & $\begin{array}{r}\text { Week } \\
4\end{array}$ & $\begin{array}{r}\text { Week } \\
5\end{array}$ & $\begin{array}{r}\text { Week } \\
6\end{array}$ & $\begin{array}{r}\text { Week } \\
7\end{array}$ & $\begin{array}{r}\text { Week } \\
8\end{array}$ & $\begin{array}{r}\text { Week } \\
9\end{array}$ & $\begin{array}{l}\text { Week } \\
10\end{array}$ \\
\hline \multicolumn{11}{|c|}{ Number of forum contributions per week } \\
\hline DD & 703 & 237 & 283 & 285 & 108 & 94 & 69 & 57 & 24 & 85 \\
\hline \multicolumn{11}{|l|}{$\mathbf{A}$} \\
\hline FP & 1,331 & 914 & 1,084 & 747 & 960 & 828 & 653 & 646 & -- & -- \\
\hline TP & 1,839 & 825 & 357 & 224 & 38 & -- & -- & -- & -- & -- \\
\hline \multicolumn{11}{|l|}{$\mathbf{M}$} \\
\hline \multicolumn{11}{|c|}{ Number of posters contributing per week } \\
\hline DDA & 304 & 104 & 106 & 89 & 48 & 44 & 23 & 24 & 16 & 41 \\
\hline FP & 392 & 292 & 219 & 181 & 177 & 174 & 177 & 154 & -- & -- \\
\hline TPM & 693 & 364 & 186 & 119 & 30 & -- & -- & -- & -- & -- \\
\hline
\end{tabular}

Table 3

Total Weeks of Contribution Per Poster

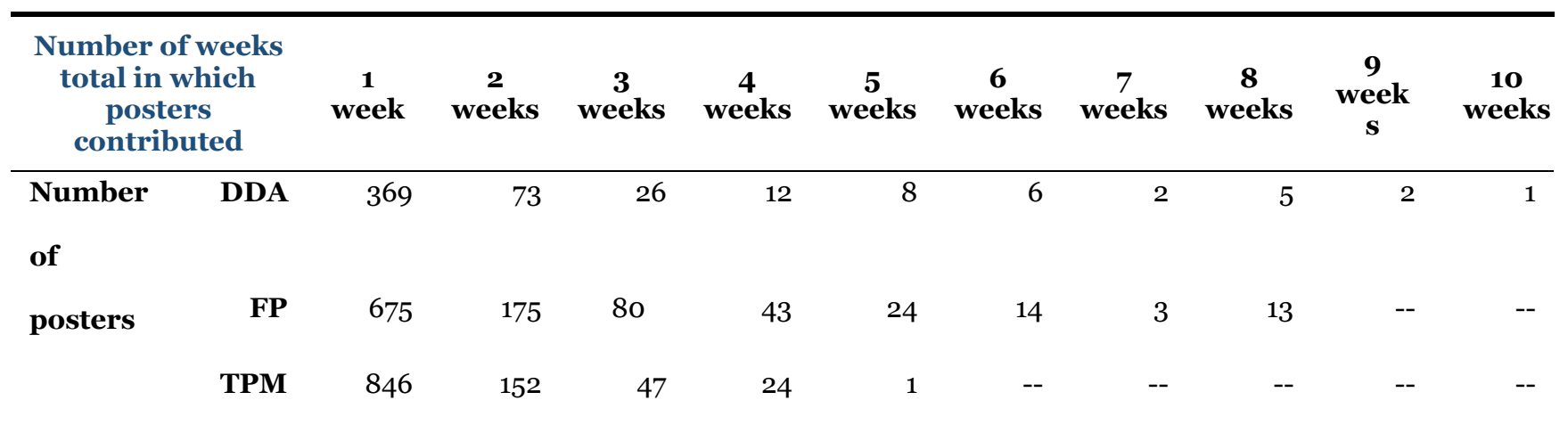


Course 3: Creative Problem Solving and Decision Making. The third course was DelftX TPM1X (Creative Problem Solving and Decision Making, or TPM). This five-week course was delivered by the Faculty of Technology, Policy, and Management. It enrolled 32,424 students. Of the total enrolled student cohort 1,396 received certificates of completion. TPM was shorter in duration than either DDA or FP. The course was designed so that each week had a distinct focus, with the course outcomes being assessed through weekly quizzes. No activities were designed to facilitate forum participation. Forum activity in the TPM course experienced a steep drop in activity not only from the first to the second week of the course, but for each consecutive week (see Table 2, above). No MOOC participants in this course interacted with another participant every week of the course (see Table 3, above). That is, the group of regular posters comprised a very small percentage of all forum users, and the volume of activity in this course was smaller than in the first two courses.

Overall, 511 CoI surveys were completed at the end of TPM. Among the respondents, 27 individuals were regular posters, 37 occasional posters, and 347 were non-posting participants. As in the other two courses, the sample mostly represented certified students but included those who audited and those who became disengaged sometime during the course.

\section{Instruments}

The respondents provided answers to nine questions from the CoI instrument (Arbaugh et al., 2008) about their perceptions of social presence in the respective courses. The students were asked to agree or disagree with the statements on a five-point Likert scale (from 1-5). The first three questions addressed students' affective expression; questions 4 though 6 addressed perceptions of the open communication, and the questions 7 through 9 inquired about the perceptions related to group cohesion. Table 6 (below) includes the instrument's questions.

\section{Data Analysis}

A series of nonparametric Kruskal-Wallis tests for each of the nine survey items investigated whether there were significant differences in social presence scores among the groups of students. Given that the survey items used an ordinal Likert scale, and that there were differences in the size of the three groups of students, we opted for the use of nonparametric significance tests. To control for the inflated Type I error rate that may result from multiple consequent comparisons, we used the Holm-Bonferroni correction procedure (Holm, 1979). This procedure offered more statistical power than the ordinary Bonferroni correction while preserving a strict control over family-wise error rate (FWER) (Holm, 1979). The significant Kruskal-Wallis tests $(p<.05)$ were then followed up with a Dunn test, also with a Holm-Bonferroni correction.

\section{Analysis}

\section{RQ1. What Does Social Presence in MOOCs Look Like When Evaluated Across the Entire Group of Forum Users Through the Social Presence Aspect of the Col Instrument?}

The results of CoI survey suggest that MOOC learners who completed the post-course questionnaire established some degree of social presence. The average scores for different survey questions varied between 2.7 to 3.9 (on a 1-5 scale; see Figure 1, below). Unfortunately, these scores cannot be statistically compared to 
those previously reported in the studies of formal online education (since the scores represent ranked data within the subgroups of varying size).

From a descriptive point of view, social presence scores previously reported in formal online courses were typically higher than 3.0 and are collected from groups of 10 to15 people interacting in courses lasting for up to 16 weeks. For instance, Akyol et al. (2009) reported a range of 3.94 to 4.30; the students in the study by Swan et al. (2008) yielded a mean social presence score of 4.18. Other studies have observed ranges of 3.67 to 4.06 (Maddrell, Morrison, \& Watson, 2011); 2.97 to 3.47 (Lowenthal, Lowenthal, \& White, 2009); and an average of 3.85 (Lowenthal \& Dunlap, 2011). It appears that in the examined MOOC settings, where larger groups of learners interacted for a shorter time than in previously-examined formal online courses, social presence could be established. This generally supports the observations of previous work investigating social presence in MOOCs.

Consistent patterns of social presence evaluation are observed across the courses, with affective expression (Q1-Q3) being rated as lowest, and open communication (Q4-Q6) rated as highest. In their analyses of social presence development over time, Akyol and Garrison (2008) pointed out that open communication, along with affective expression, is the most prominent in the initial stages of social presence development, whereas group cohesion slowly grows over time as the group identity forms. It is, then, noteworthy that the affective expression of the learners yielded the lowest scores, which is in contrast to what would be expected from formal online settings. Reported open communication and group cohesion, however, can be interpreted as aligned with what has been observed in other educational contexts. 


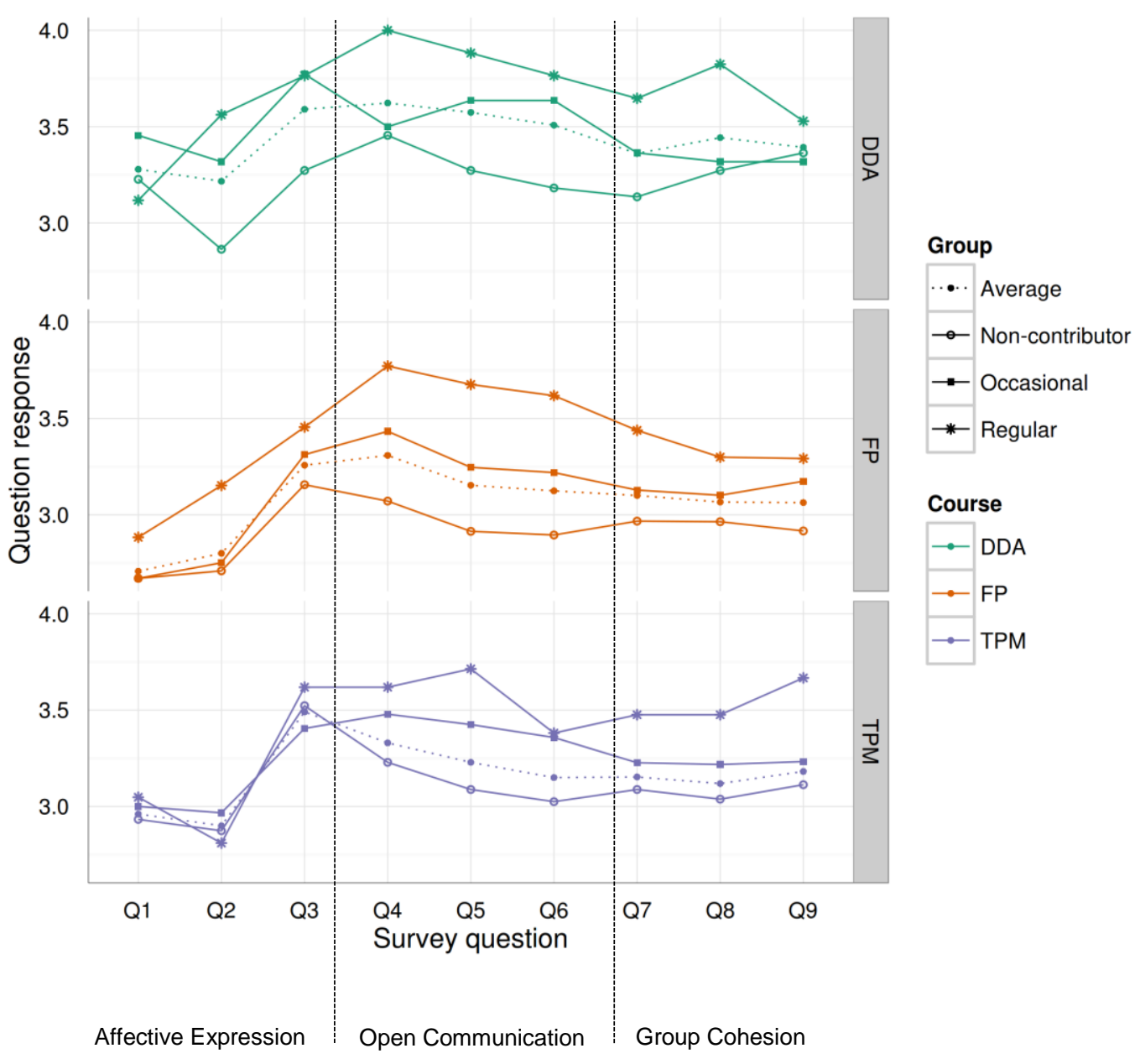

Figure 1. Students' social presence scores for each of the survey question (per group, per course).

There are also substantial differences in the levels of social presence established. The size of the posting cohort and the duration of the MOOC seem to be associated with the levels of social presence reported across the entire sample. The highest scores for social presence (range: $3.2-3.7$ ) were reported by the participants in the analysed MOOCs with the smallest number of total participants (i.e., DDA). Besides having the smallest group of regular posters, DDA had a sizable volume of forum interactions. In contrast, the size of the regular cohort and volume of interactions in TPM course was similar, but the range of average social presence was slightly lower (2.9-3.5). This could be explained by the fact that TPM lasted half the time of DDA. Finally, the lowest average social presence was observed in the massive FP course (2.7-3.3). The size of the contributing cohort in FP was three times larger than in DDA. Furthermore, the volume of interactions was much higher-for example, the last week of FP garnered about eight-times more interactions than the last week of DDA.

The properties of analysed MOOCs (i.e. size of the cohort, duration of the course, and the volume of interactions) may explain the differences among the social presence scores, irrespective of consideration for pedagogies that contextualise interpersonal interactions. The importance of the course duration was similarly highlighted in the meta-analysis by Richardson et al. (2017) who found that the duration of the course mediated between the social presence and satisfaction. In the analysed courses, the instructors have not given 
specific tasks that integrated the use of forums, and forum participation was not graded. Although DDA had embedded peer assessment within the course, our look at the discussions on the forum suggested that the discipline of the course had more to do with its heightened interactivity.

The most important observation to be drawn from Figure 1 is that the levels of social presence reported from the entire sample do not offer an accurate representation of the levels of social presence established in the course. The average social presence scores are skewed by the lower levels reported by the non-posting students, and by the higher levels reported by the regular forum posters (see Figure 1, above). Had we only examined average levels of social presence for the whole of each course, as has been done in the previous research of social presence in MOOCs, DDA and TPM posters would appear to have established higher levels of social presence, while the largest cohort in the FP course lagged behind. However, such observation is inaccurate since the social presence construct (conceptually) examines perceptions of those who can establish social presence in principle-that is, those who interact regularly.

A comparison of the social presence scores reported by the regular posters (see Table 4, below) suggests that the TPM regular posters' scores are more aligned with the levels of social presence in the FP course, rather than those of DDA. That is, regular posters in TPM developed lower perceptions of open communication and group cohesion than regularly-participating students undertaking $\mathrm{FP}$-and this despite a much larger cohort size in FP. Given that TPM had a smaller cohort posting, this should indicate that the social interactions within the course could have been less vibrant than expected. Further, FP's average portrays it as a course with quite low social presence, but the reported results of the regular posters are comparable with what is typically expected in a formal course. In other words, FP had a high volume of interaction in which, regardless of the large volume, posters managed to establish social presence almost as high as learners in much smaller groups, such as DDA and TPM. In conclusion, looking at the social presence scores by group demonstrates that FP and DDA were rather successful in terms of social presence, whereas TPM was less successful than expected.

As discussed, a valid comparison of social presence raw scores among the learner groups of varying engagement levels can be accomplished through the statistical analysis of differences between the groups. If applied to the entire cohort, social presence scores do not offer an accurate representation of perceptions from the regularly-participating learners.

\section{RQ2. What is the Association Between Student Perceptions of Social Presence and MOOC Discussion Forum Participation?}

The patterns reported in Figure 1 were used as exploration. Further statistical comparison of the effect of participation levels on the social presence scores of each course revealed that student engagement levels was associated with differences in the perception of social presence. However, such a conclusion was not consistent across all analysed cases (see Table 4, below).

Kruskal-Wallis tests-DDA results. In the DDA course, the results of Kruskal-Wallis H-tests did not reveal significant differences between regular posters $\left(\mathrm{n}_{\mathrm{r}}=18\right)$, occasional posters $\left(\mathrm{n}_{\mathrm{occ}}=29\right)$, and nonposters $\left(\mathrm{n}_{\mathrm{np}}=31\right)$.

Kruskal-Wallis tests-FP results. For FP, statistical comparison between the groups reveals significant differences between the social presence scores in all three groups. A Kruskal-Wallis H-test highlighted the differences in how regular $\left(\mathrm{n}_{\mathrm{r}}=117\right)$, occasional $\left(\mathrm{n}_{\mathrm{occ}}=243\right)$ and non-posting $\left(\mathrm{n}_{\mathrm{np}}=706\right)$ forum 
participants responded to the CoI survey. None of the intergroup differences was statistically significant for the questions concerning affective expression, with the exception of $\mathrm{Q}_{2}\left(\chi^{2} \mathrm{Q}_{2}(2)=18.40, p_{Q_{2}}=.00001\right)$. Specifically, Dunn's post hoc test with the Holm-Bonferroni correction shows statistically significant differences between regular and occasional posters in relation to their ability to form distinct impressions of peers in the forum $\left(r_{Q 2 r-o c c}=.22\right)$, as well as between regular posters and non-posting participants $\left(r_{Q 2 r-n p}=\right.$ $.17)$.

The differences between the three groups of forum contributors were also significant for Q4 through Q9 (in the social presence part of the CoI instrument): $\chi 2_{Q_{4}}(2)=76.36, p_{Q 4}<.0001 ; \chi 2_{Q_{5}}(2)=100.9, p_{Q_{5}}<.0001$; $\chi^{2}{ }_{Q 6}(2)=88.26, p_{Q 6}<.0001 ; \chi^{2}{ }_{Q 7}(2)=54.14, p_{Q 7}<.0001 ; \chi_{28}(2)=32.12, p_{Q 8}<.0001 ; \chi^{2}{ }_{Q 9}(2)=17.33, p_{Q 9}<$ .0001. For all questions related to open communication (Q4-Q6), the degree of participation exerted a smallto-moderate effect in all three groups of participants. The differences between regular and non-posting participants were higher $\left(r_{Q 4 r-n p}=.31 ; r_{Q 5 r-n p}=.38 ; r_{Q 6 r-n p}=.35\right)$ than those between regular and occasional posters $\left(r_{Q 4 r-o c}=.21 ; r_{Q 5 r-o c}=.28 ; r_{Q 6 r-o c}=.25\right)$ and those between occasional and non-posting participants $\left(r_{Q 4 o c-}\right.$ ${ }_{n p}=.21 ; r_{Q 5 o c-n p}=.2 ; r_{Q 6}$ oc-np $\left.=.19\right)$. To summarize, the findings demonstrate a positive association between the level of learner participation and the level of comfort to converse online, to participate in the course discussions, and to interact with others on the forum.

Similar dynamics are reflected in the survey questions addressing group cohesion. All groups presented significant differences. The findings demonstrate that participation levels had a small effect on group cohesion perceptions $\left(r_{Q 7 r-o c c}=.22 ; r_{Q 7 r-n p}=.28 ; r_{Q 7 o c-n p}=.13 ; r_{Q 8 r-o c c}=.16 ; r_{Q 8 r-n p}=.22 ; r_{Q 8 o c c-n p}=.11 ; r_{Q 9 r-o c c}=.11 ; r_{Q 9 r-n p}\right.$ $\left.=.16 ; r_{Q 9 o c-n c}=.09\right)$. As with other survey questions, regular posters reported the highest levels of comfort in disagreeing with others, and in being acknowledged by others (see Table 4, below). 
Table 4

Kruskal-Wallis Results

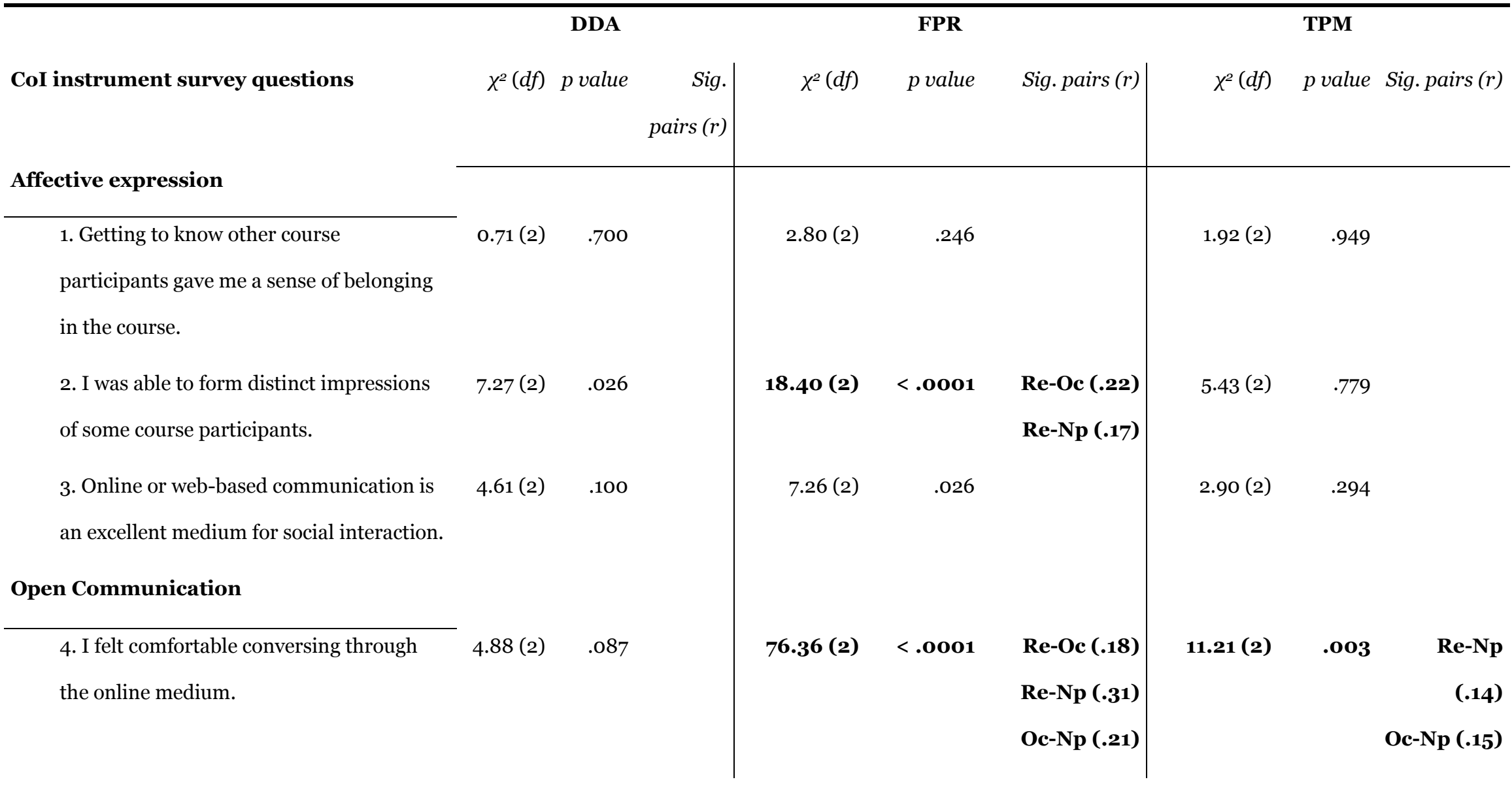


Poquet, Kovanović, de Vries, Hennis, Joksimović, Gašević, and Dawson

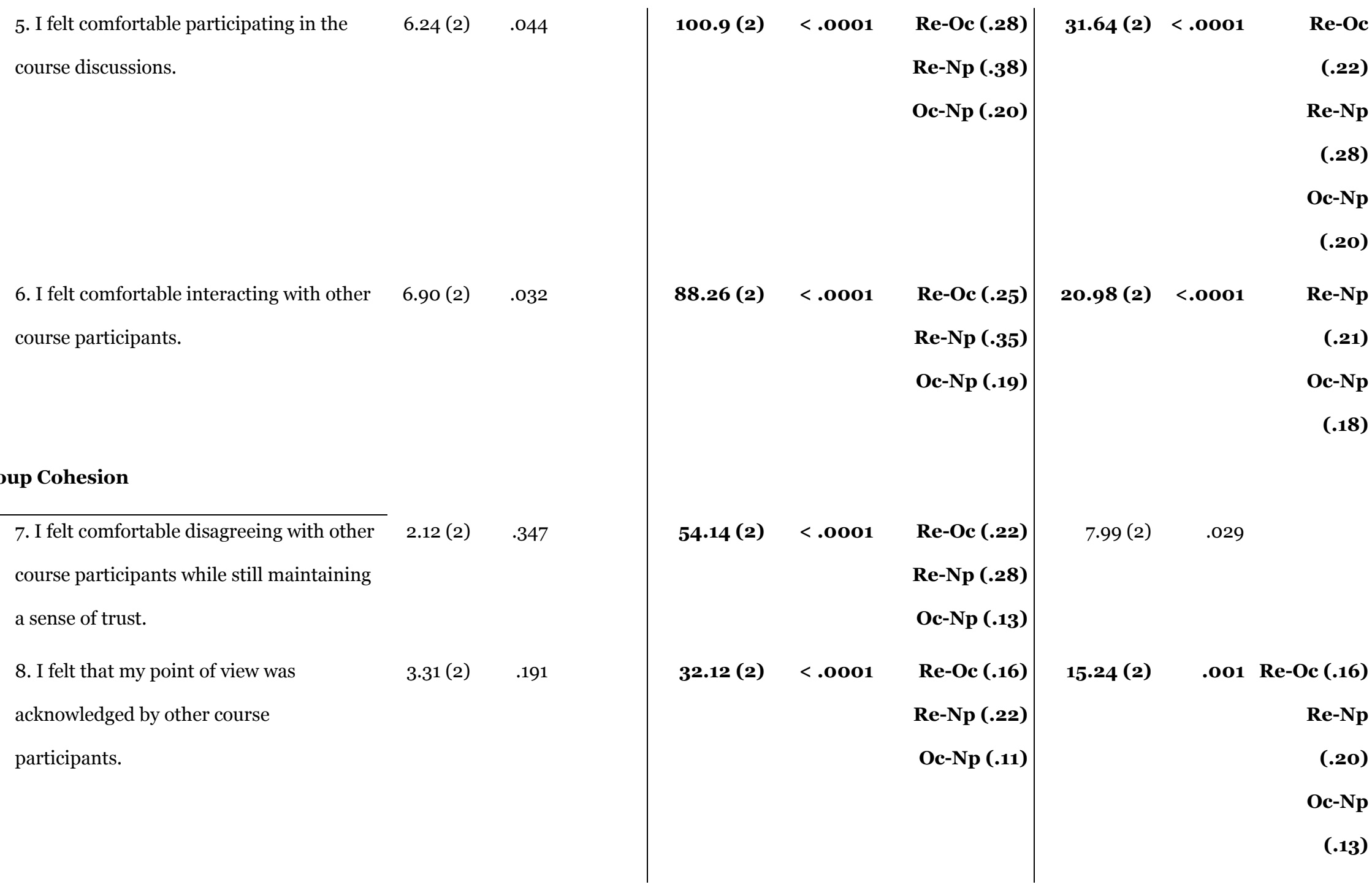


Table 5

Mean (SD) Values for Social Presence Survey Question Responses

\begin{tabular}{|c|c|c|c|c|c|c|c|c|c|}
\hline & \multicolumn{3}{|c|}{ Affective expression } & \multicolumn{3}{|c|}{ Open communication } & \multicolumn{3}{|c|}{ Group cohesion } \\
\hline & $Q 1$ & Q2 & Q3 & Q4 & Q5 & Q6 & Q7 & Q8 & Q9 \\
\hline \multicolumn{10}{|l|}{ DDA } \\
\hline Regular posters & $3.12(0.99)$ & $3.56(0.81)$ & $3.76(1.20)$ & $4.00(0.87)$ & $3.88(0.86)$ & $3.76(0.83)$ & $3.65(1.00)$ & $3.82(0.73)$ & $3.53(1.18)$ \\
\hline Occasional posters & $3.45(0.91)$ & 3.32 (1.09) & $3.77(0.92)$ & $3.50(0.91)$ & $3.64(1.00)$ & $3.64(0.95)$ & $3.36(0.95)$ & $3.32(0.99)$ & 3.32 (1.13) \\
\hline Non-posting participants & $3.23(0.81)$ & $2.86(0.77)$ & $3.27(0.88)$ & $3.45(0.80)$ & $3.27(0.70)$ & $3.18(0.66)$ & $3.14(0.56)$ & $3.27(0.63)$ & $3.36(0.66)$ \\
\hline Entire group & $3.28(0.90)$ & $3.22(0.94)$ & $3.59(1.01)$ & $3.62(0.88)$ & $3.57(0.88)$ & $3.51(0.85)$ & $3.36(0.86)$ & $3.44(0.83)$ & 3.39 (0.99) \\
\hline
\end{tabular}




\begin{tabular}{|c|c|c|c|c|c|c|c|c|c|}
\hline FP & & & & & & & & & \\
\hline Regular posters & $\begin{array}{r}\mathbf{2 . 8 8} \\
(0.87)\end{array}$ & $\begin{array}{r}3.15 \\
(1.00)\end{array}$ & $\begin{array}{r}3.46 \\
(1.00)\end{array}$ & $3 \cdot 77(0.85)$ & $\begin{array}{r}3.68 \\
(0.86)\end{array}$ & $\begin{array}{r}3.62 \\
(0.79)\end{array}$ & $\begin{array}{r}3.44 \\
(0.71)\end{array}$ & $\begin{array}{r}3.30 \\
(0.74)\end{array}$ & $\begin{array}{r}3.29 \\
(0.87)\end{array}$ \\
\hline Occasional posters & $\begin{array}{r}\mathbf{2 . 6 7} \\
(\mathbf{0 . 8 6 )}\end{array}$ & $\begin{array}{r}2.75 \\
(0.94)\end{array}$ & $\begin{array}{r}\mathbf{3 . 3 1} \\
(\mathbf{0 . 8 5})\end{array}$ & $3.43(0.86)$ & $\begin{array}{r}3.25 \\
(0.84)\end{array}$ & $\begin{array}{r}3.22 \\
(0.81)\end{array}$ & $\begin{array}{r}3.13 \\
(0.67)\end{array}$ & $\begin{array}{r}3.10 \\
(0.60)\end{array}$ & $\begin{array}{r}\mathbf{3 . 1 7} \\
(\mathbf{0 . 8 2})\end{array}$ \\
\hline Non-posting participants & $\begin{array}{r}2.67 \\
(0.80)\end{array}$ & $\begin{array}{r}2.71 \\
(0.87)\end{array}$ & $\begin{array}{r}3.16 \\
(0.86)\end{array}$ & $3.07(0.84)$ & $\begin{array}{r}2.91 \\
(0.77)\end{array}$ & $\begin{array}{r}2.90 \\
(0.75)\end{array}$ & $\begin{array}{r}\mathbf{2 . 9 7} \\
(\mathbf{0 . 7 0 )}\end{array}$ & $\begin{array}{r}2.96 \\
(0.59)\end{array}$ & $\begin{array}{r}2.92 \\
(0.72)\end{array}$ \\
\hline Entire group & $\begin{array}{r}2.71 \\
(0.84)\end{array}$ & $\begin{array}{r}2.80 \\
(0.93)\end{array}$ & $\begin{array}{r}3.26 \\
(0.89)\end{array}$ & 3.31 (o.89) & $\begin{array}{r}3.15 \\
(0.86)\end{array}$ & $\begin{array}{r}3.12 \\
(0.82)\end{array}$ & $\begin{array}{r}3.10 \\
(0.71)\end{array}$ & $\begin{array}{r}3.07 \\
(0.64)\end{array}$ & $\begin{array}{r}3.06 \\
(0.79)\end{array}$ \\
\hline TPM & & & & & & & & & \\
\hline Regular posters & $3.05(0.97)$ & $2.81(1.08)$ & $3.62(0.92)$ & $3.62(1.02)$ & $\begin{array}{r}3.71 \\
(0.78)\end{array}$ & $\begin{array}{r}3.38 \\
(0.86)\end{array}$ & $3.48(0.68)$ & $\begin{array}{r}3.48 \\
(0.60)\end{array}$ & $\begin{array}{r}3.67 \\
(0.91)\end{array}$ \\
\hline Occasional posters & $3.00(0.75)$ & $2.97(0.74)$ & $3.40(0.98)$ & $3.48(0.85)$ & $\begin{array}{r}3.42 \\
(0.73)\end{array}$ & $\begin{array}{r}3.36 \\
(0.71)\end{array}$ & $3.23(0.79)$ & $\begin{array}{r}3.22 \\
(0.61)\end{array}$ & $\begin{array}{r}3.23 \\
(0.91)\end{array}$ \\
\hline Non-posting participants & $2.93(0.79)$ & $2.87(0.82)$ & $3.52(0.87)$ & $3.23(0.86)$ & $\begin{array}{r}3.09 \\
(0.79)\end{array}$ & $\begin{array}{r}3.03 \\
(0.78)\end{array}$ & $3.09(0.75)$ & $\begin{array}{r}3.04 \\
(0.69)\end{array}$ & $\begin{array}{r}3.11 \\
(0.78)\end{array}$ \\
\hline Entire group & $2.83(0.75)$ & $2.90(0.81)$ & $3.49(0.91)$ & $3.33(0.87)$ & $\begin{array}{r}3.23 \\
(0.79)\end{array}$ & $\begin{array}{r}3.15 \\
(0.78)\end{array}$ & $3.15(0.76)$ & $\begin{array}{r}3.12 \\
(0.67)\end{array}$ & $\begin{array}{r}3.18 \\
(0.84)\end{array}$ \\
\hline
\end{tabular}

Note. Results in bold indicate significant differences in mean ranks between groups. 
Kruskal-Wallis tests-TPM results. Analysis of the affective expression perceptions in the TPM course shows no significant differences between regular forum posters $\left(\mathrm{n}_{\mathrm{r}}=27\right)$, occasional forum posters $\left(\mathrm{n}_{\mathrm{oc}}\right.$ $=137)$ and non-posters $\left(n_{n p}=347\right)$. That is, students formed impressions of others and developed a sense of community at the average and below-average levels regardless of their level of discussion activity. Such results are comparable to those of DDA, though generally DDA scores were slightly higher.

For TPM, significant differences were observed between the groups of regular posters and non-posters for open communication and, partially for group cohesion. As in FP, non-posters reported significantly lower levels of open communication $(\mathrm{Q} 4-\mathrm{Q} 6)$ than regular and occasional forum posters $\left(\chi 2_{Q 4}(2)=11.21, p_{Q 4}=.003 ; \chi_{2}{ }_{Q 5}(2)\right.$ $\left.=31.64, p_{Q 5}<.0001 ; \chi 2_{Q 6}(2)=20.98, p_{Q 6}<.0001\right)$. However, no differences exist in open communication between regular and occasional posters. In the TPM course, there were also no differences in how students evaluated their comfort to disagree with others while maintaining a sense of trust (i.e., Q7). The remaining group cohesion-related questions (Q8-Q9) all demonstrated a significant difference between the groups of varying participation levels $\left(\chi 2_{Q 8}(2)=15.24, p_{Q 8}=.001 ; \chi 2_{Q 9}(2)=18.37, p_{Q 9}<.01\right)$. Small-effect differences were observed between the regular posters and non-posting participants $\left(r_{Q 8 r-n p}=.2 ; r_{Q 9 r-n p}=.25\right)$, as well as between regular and occasional posters $\left(r_{Q 8 r-o c}=.16\right.$; $\left.r_{Q 9 r-o c}=.26\right)$, and between occasional posters and nonposting participants $\left(r_{Q 8 o c-n p}=.13 ; r_{Q 9 o c-n p}=.1\right)$.

\section{Discussion}

This study examined the perceptions of social presence in three platform-based MOOC forums. From a practical perspective, online educators have long emphasized that establishing the social presence through sustained learner interactions in formal courses aids their engagement and motivation. Similarly, the establishment of social presence in open online courses such as MOOCs can help learners overcome the feeling of anonymity and solitude they experience within scaled interactions, as well as yield benefits from peer interactions that reach beyond simple information exchange. From a research perspective, few studies examined social presence in MOOC settings, and their findings were limited due to the lack of accounting for the unique characteristics of MOOC environments. We argued that MOOC discussion forums do not possess the interaction dynamics of the formal, small-scale online courses, and that researchers need to account for the differences between these two contexts carefully.

In lieu of conducting an evaluation of social presence based on the entire sample of respondents across the three analysed courses, we investigated social presence scores for different learner sub-populations in each course and compared the level of participation (i.e., regular poster, occasional poster, and nonposting participants) in the online discussions with perceived levels of social presence. The study found that perceptions of social presence differed between the learner subpopulations with different forum activity levels. The analysis also revealed that the overall evaluation of social presence within a MOOC differs (1) when the social presence scores were collected from individuals who continuously participated in the forums; versus (2) when the social presence scores were averaged from all the respondents. This is a significant finding because social presence scores in MOOCs have not been previously examined across learner subpopulations. The results demonstrate that learners who participated continuously established their social presence at levels above the group average. This suggests that instructors may not need to foster social presence for all learners joining the forums, and that evaluating established social presence at the end of the course is more meaningful when examined from regularly-participating individuals. 
Our study also revealed that perceived levels of social presence varied between courses with different durations and levels of forum interactions. This finding is in line with the role given to course duration in the metaanalysis by Richardson et al. (2017). Previous studies (Lowry, Roberts, Romano, Cheney, \& Hightower, 2006; $\mathrm{Tu}, 2002$, among others) identified that the size of discussion groups is among the key aspects that affect student level of participation and interactivity, with larger groups having adverse effects on student discussion participation. In the present study, we observed that learners could establish a considerably high perceived levels of social presence. Our findings imply that the expected effect of the size and duration of a course is heightened in a MOOC. Among the three MOOCs investigated, the highest level of social presence was reported in the course with the smallest number of students (i.e., DDA), with no significant differences between the perceptions among learner subpopulations. However, in two larger courses (i.e., FP and TPM), social presence varied in line with the level of student activity on the forum: posters whose interactions were continuous and more regular reported higher levels of social presence than those who participated passively. The lack of differences in perceptions among the different learners in DDA could be explained as follows. In the course with the smaller group of active discussion participants, both passive and active participants can comprehend the volume of activity enough to establish social presence perceptions. However, in courses with larger volumes of activity, and with more active participants, students need to continuously participate to establish their social presence. Hence, our findings suggest that the size of the posting cohort and the duration of the course serve as mediating factors in the establishment of social presence. The scope of the impact of these findings needs to be further validated in future research.

Learners with sustained discussion activity generally reported higher social presence scores that included low affectivity and strong perceptions of group cohesion. The development of the affective dimension of social presence among discussion participants seemed to be the most challenging across all three analysed courses. Despite engaging in conversations and demonstrating higher comfort and more positive attitudes regarding the use of technology for in-course communication, even the students in DDA (the smallest course in size, and the course with the highest social presence perceptions) evaluated the establishment of familiarity, emotional connection, and sense of trust as low. On the other hand, group cohesion was reported as being highest by the same groups of learners. These findings are in line with the validation of the CoI instrument by Kovanovic et al. (2017) who found that affective expression can be approached separately from the social presence construct. In other words, it appears that social presence in MOOCs is not based on affective interpersonal relations, but-despite the lack of interpersonal familiarity-group-related processes (open communication and group cohesion) may still be taking place.

Learner reporting of low affectivity and high group cohesion raises questions about the relevance of measuring social presence in MOOCs similar to the formal online educational settings. In the theories of formal online education, constructs related to the social context are dependent on an interpersonal one-to-one level of interaction and salience of the self. Despite references to the collective level, social context and identity within the overall conceptualisations of social presence in both Gunawardena and Zittle (1997) and Arbaugh et al. (2008) measure such one-to-one perceptions. More recently, Kreijns et al. (2014) and Weidlich and Basianens (2017) hypothesised that a person-to-person (dyadic) level construct reflecting impression-formation is a precursor of the group-level relational construct of social space. It could be extrapolated from our findings that in MOOC settings, given the lack of salience of the self and learner-reported perceptions of low affectivity and high group cohesion, relational perceptions of the group are not dependent on interpersonal relationships and unfold independently. 
To offer further recommendations, analysis of social presence should be coupled with pedagogical designs; this was beyond the focus of this study. Also, our findings have some limitations that impact their generalisability. The present study was based on a small sample of courses delivered through the same MOOC platform, and the impact of contextual factors (i.e., size of posting cohort, duration of the course) is speculative. Further, the study did not investigate the relationship between the student perceptions of social presence and pedagogical and instructional contexts of the courses. For this course, the discipline context could be considered as more conducive to social interactions. Each of the courses we analysed had some distinct features, but understanding if these planned elements were effective, or concluding that they had effect on interactions, is not possible. That is, a more elaborate research design is needed to understand the interation of course learning design, discipline, forum facilitation strategy; and volume of interaction, duration, size of regularly posting cohort. The same is true for the affect these factors have on student social presence perceptions.

\section{Conclusion}

This study has provided the first steps of the investigation into the development of social presence in MOOC contexts. The study's research design integrated methodological considerations to make social presence examination specific to the educational context with scaled and open participation. It is evident that, even at scale, some courses offer more affordances for the establishment of social presence than others. However, methods of evaluating social presence are to be carefully considered. Although students reported that they established social presence, as measured by the CoI survey instrument, it is peculiar that their sense of trust remained low, tapping into whether the definition of social presence as underpinned by an interpersonal (person-to-person) emotional connection is at all relevant for a massive open online environment. The empirical results of this study contribute to the body of knowledge around social presence and raise questions about the transference of socio-constructivist constructs into the context of open online learning. 


\section{References}

Akyol, Z., \& Garrison, D. R. (2008). The development of a community of inquiry over time in an online course: Understanding the progression and integration of social, cognitive and teaching presence. Journal of Asynchronous Learning Networks, 12(3-4), 3-22.

Akyol, Z., Garrison, D. R., \& Ozden, M. Y. (2009). Online and blended communities of inquiry: Exploring the developmental and perceptional differences. The International Review of Research in Open and Distributed Learning, 10(6), 65-83. http://doi.org/10.19173/irrodl.v10i6.765

Appiah-Kubi, K., \& Rowland, D. (2016). PEER support in MOOCs: The role of social presence. In Proceedings of the Third (2016) ACM Conference on Learning @ Scale (pp. 237-240). New York: ACM. https://doi.org/10.1145/2876034.2893423

Arbaugh, J. B., \& Benbunan-Fich, R. (2006). An investigation of epistemological and social dimensions of teaching in online learning environments. Academy of Management Learning \& Education, 5(4), 435-447.

Arbaugh, J. B., Cleveland-Innes, M., Diaz, S. R., Garrison, D. R., Ice, P., Richardson, J. C., \& Swan, K. P. (2008). Developing a community of inquiry instrument: Testing a measure of the community of inquiry framework using a multi-institutional sample. The Internet and Higher Education, 11(3-4), 133-136. https://doi.org/10.1016/j.iheduc.2008.06.003

Bergner, Y., Kerr, D., \& Pritchard, D. E. (2015). Methodological challenges in the analysis of MOOC data for exploring the relationship between discussion forum views and learning outcomes. In O. Santos, J. Boticario, C. Romero, M. Pechenizkiy, A. Merceron, P. Mitros, J. ... M. Desmarais (Eds.), Proceedings of the 8th International Conference on Educational Data Mining (EDM'15), Madrid, Spain (pp. 234-241). Retrieved from http://www.educationaldatamining.org/EDM2015/uploads/papers/paper 61.pdf

Boroujeni, M., Hecking, T., Hoppe, H. U., \& Dillenbourg, P. (2017). Dynamics of MOOC discussion forums. In Proceedings of the 7th International Learning Analytics and Knowledge Conference (LAK17), 128-137. http://doi.org/10.1145/3027385.3027391

Boston, W. E., Ice, P., Díaz, S. R., Richardson, J., Gibson, A. M., \& Swan, K. (2009). An exploration of the relationship between indicators of the community of inquiry framework and retention in online programs. Journal of Asynchronous Learning Networks, 13(3), 67-83.

Bransford, J., Brown, A., \& Cocking, R. (2000). How people learn. Washington, DC: National Academy Press.

Carlon, S., Bennett-Woods, D., Berg, B., Claywell, L., LeDuc, K., Marcisz, N. ... Zenoni, L. (2012). The community of inquiry instrument: Validation and results in online health care disciplines. Computers \& Education, 59(2), 215-221. https://doi.org/10.1016/j.compedu.2012.01.004

Cheung, E. (2014). Analyzing student engagement and retention in Georgetown's first MOOC: Globalization's winners and losers: Challenges for developed and developing Countries. (Master's 
thesis, Georgetown University, Washington, DC). Retrieved from http://hdl.handle.net/10822/709735

Coffrin, C., Corrin, L., de Barba, P., \& Kennedy, G. (2014). Visualizing patterns of student engagement and performance in MOOCs. In Proceedings of the Fourth International Conference on Learning Analytics and Knowledge (LAK'14), 83-92. https://dx.doi.org/10.1145/2567574.2567586

Damm, C. A. (2016). Applying a community of inquiry instrument to measure student engagement in large online courses. Current Issues in Emerging eLearning, 3(1).

Daniel, J. (2012). Making sense of MOOCs: Musings in a maze of myth, paradox and possibility. Journal of Interactive Media in Education, 3(18). http://doi.org/10.5334/2012-18

Díaz, S. R., Swan, K., Ice, P., \& Kupczynski, L. (2010). Student ratings of the importance of survey items, multiplicative factor analysis, and the validity of the community of inquiry survey. The Internet and Higher Education, 13(1), 22-30.

Dillenbourg, P., Baker, M., Blaye, A., \& O’Malley, C. (1996). The evolution of research on collaborative learning. In E. Spada \& P. Reiman (Eds.), Learning in humans and machine: Towards an interdisciplinary learning science (pp. 189- 211). Oxford, England: Elsevier.

Eynon, R., Gillani, N., Hjorth, I., and Yasseri, T. (2014). Conceptualising interaction and learning in MOOCs. MOOC Research Initiative. Retrieved from http://lntrg.education.ox.ac.uk/projects/conceptualising-interaction-and-learning-in-moocs/

Ferguson, R., \& Clow, D. (2015). Examining engagement: Analysing learner subpopulations in massive open online courses (MOOCs). In Proceedings of the Fifth International Conference on Learning Analytics and Knowledge (pp. 51-58). Poughkeepsie, New York: ACM. https://doi.org/10.1145/2723576.2723606

Garrison, D. R. (2009). Communities of inquiry in online learning. In P. L. Rogers, G. A. Berg, J. V. Boettcher, L. Howard, L. Justice, \& K. D. Schenk (Eds.), Encyclopedia of distance learning (2nd ed., pp. 352-355). Hershey, PA: IGI Global.

Garrison, D. R., \& Akyol, Z. (2013). The community of inquiry theoretical framework. In M. G. Moore (Ed.), Handbook of Distance Education (3rd ed., pp. 104-119). Routledge.

Garrison, D. R., Anderson, T., \& Archer, W. (1999). Critical inquiry in a text-based environment: Computer conferencing in higher education. The Internet and Higher Education, 2(2-3), 87-105. https://doi.org/10.1016/S1096-7516(00)00016-6

Garrison, D. R., Cleveland-Innes, M., \& Fung, T. S. (2010). Exploring causal relationships among teaching, cognitive and social presence: Student perceptions of the community of inquiry framework. The Internet and Higher Education, 13(1), 31-36. https://doi.org/10.1016/j.iheduc.2009.10.002 
Gunawardena, C. N. (1995). Social presence theory and implications for interaction and collaborative learning in computer conferences. International Journal of Educational Telecommunications, 1(2), 147-166.

Gunawardena, C. N., \& Zittle, F. J. (1997). Social presence as a predictor of satisfaction within a computermediated conferencing environment. American Journal of Distance Education, 11(3), 8-26. http://doi.org/10.1080/08923649709526970

Gutiérrez-Santiuste, E., Rodríguez-Sabiote, C., \& Gallego-Arrufat, M.-J. (2015). Cognitive presence through social and teaching presence in communities of inquiry: A correlational-predictive study. Australasian Journal of Educational Technology, 31(3). https://doi.org/10.14742/ajet.1666

Hecking, T., Chounta, I.-A., \& Hoppe, H. U. (2016). Investigating social and semantic user roles in MOOC discussion forums. In Proceedings of the Sixth International Conference on Learning Analytics \& Knowledge (pp. 198-207). http://doi.org/10.1145/2883851.2883924

Holm, S. (1979). A simple sequentially rejective multiple test procedure. Scandinavian Journal of Statistics, 6(2), 65-70.

Johnson, D. W. (1981). Student-student interaction: The neglected variable in education. Educational Researcher, 1O(1), 5-10. https://doi.org/10.3102/0013189X010001005

Joksimović, S., Gašević, D., Kovanović, V., Riecke, B. E., \& Hatala, M. (2015). Social presence in online discussions as a process predictor of academic performance. Journal of Computer Assisted Learning, 31(6), 638-654. https://doi.org/10.1111/jcal.12107

Kilgore, W., \& Lowenthal, P. (2015). The human element MOOC: An experiment in social presence. In R. D. Wright (Ed.), Student-teacher interaction in online learning environments (pp. 373-391). Hershey, PA: IGI Global.

Kim, J., Song, H., \& Luo, W. (2016). Broadening the understanding of social presence: Implications and contributions to the mediated communication and online education. Computers in Human Behavior, 65, 672-679. https://doi.org/10.1111/jcal.12107

Kizilcec, R., Piech, C., \& Schneider, E. (2013). Deconstructing disengagement: Analyzing learner subpopulations in massive open online courses. In Proceedings of the Third International Conference on Learning Analytics and Knowledge (LAK'13) (pp. 170-179).

https://doi.org/10.1145/2460296.2460330

Kop, R., \& Fournier, H. (2013). Social and affective presence to achieve quality learning in MOOCs. In World Conference on E-Learning in Corporate, Government, Healthcare, and Higher Education (Vol. 2013, pp. 1977-1986). Association for the Advancement of Computing in Education (AACE), Chesapeake, VA 
Kovanović, V., Joksimovic, S., Poquet, O., Hennis, T., Cukic, I., de Vries, P., ... Gasevic, D. (2018). Exploring communities of inquiry in massive open online courses. Computers and Education, 118, 44-58. http://doi.org/10.1016/j.compedu.2017.11.010

Kreijns, K., Kirschner, P. A., Jochems, W., \& Buuren, H. (2011). Measuring perceived social presence in distributed learning groups. Education and Information Technologies, 16(4), 365-381.

https://doi.org/10.1007/s10639-010-9135-7

Kreijns, K., Van Acker, F., Vermeulen, M., \& Van Buuren, H. (2014). Community of inquiry: Social presence revisited. E-Learning and Digital Media, 11(1), 5-18. https://doi.org/10.2304/elea.2014.11.1.5

Liu, S. Y., Gomez, J., \& Yen, C.-J. (2009). Community college online course retention and final grade: Predictability of social presence. Journal of Interactive Online Learning, 8(2).

Lowenthal, P. R. (2009). The evolution and influence of social presence theory on online learning. In S. Dasgupta (Ed.), Social computing: Concepts, methodologies, tools, and applications (pp. 113-128). Hershey, PA: IGI Global.

Lowenthal, P. R., \& Dunlap, J. (2011, April). Investigating students' perceptions of various instructional strategies to establish social presence. Paper presented at the annual meeting of the American Educational Research Association, New Orleans, LA.

Lowenthal, P. R., Lowenthal, D. A., \& White, J. W. (2009). The changing nature of online communities of inquiry: An analysis of how discourse and time shapes students' perceptions of presence. In M. Simonson (Ed.), 32nd Annual proceedings: Selected research and development papers presented at the annual convention of the Association for Educational Communications and Technology. Washington DC: Association for Educational Communications and Technology.

Lowry, P. B., Roberts, T. L., Romano, N. C., Cheney, P. D., \& Hightower, R. T. (2006). The impact of group size and social presence on small-group communication: Does computer-mediated communication make a difference? Small Group Research, 37(6), 631-661.

https://doi.org/10.1177/1046496406294322

Maddrell, J. A., Morrison, G. R., \& Watson, G. S. (2011, November). Community of inquiry framework and learner achievement. Paper presented at the annual meeting of the Association of Educational Communication \& Technology, Jacksonville, FL.

Milligan, C., Littlejohn, A., \& Margaryan, A. (2013). Patterns of engagement in connectivist MOOCs. MERLOT Journal of Online Learning and Teaching, 9(2), 149-159.

Na Ubon, A., \& Kimble, C. (2004). Exploring social presence in asynchronous text-based online learning communities. In Proceedings of the 5th International Conference on Information Communication Technologies in Education 2004 (pp. 292-297). IEEE.

Picciano, A. G. (2002). Beyond student perceptions: Issues of interaction, presence, and performance in an online course. Journal of Asynchronous Learning Networks, 6(1), 21-40. 
Poquet, O. (2017). Social context in MOOCs. (Doctoral thesis). University of South Australia. Retrieved from https://www.researchgate.net/profile/Oleksandra_Poquet/publication/318529710_Social_Context in Massive_Open_Online_Courses/links/596f279da6fdcc24169467e3/Social-Context-in-MassiveOpen-Online-Courses.pdf

Poquet, O., Dowell, N., Brooks, C., \& Dawson, S. (2018). Are MOOC forums changing? In LAK '18 Proceedings of the 8th International Conference on Learning Analytics and Knowledge, 340-349. http://doi.org/10.1145/3170358.3170416

Richardson, J. C., Maeda, Y., Lv, J., \& Caskurlu, S. (2017). Social presence in relation to students' satisfaction and learning in the online environment: A meta-analysis. Computers in Human Behavior, 71, 402417. https://doi.org/10.1016/j.chb.2017.02.001

Rodrigues, R. L., Ramos, J. L., Silva, J. C. S., Gomes, A. S., de Souza, F. da F., \& Maciel, A. M. A. (2016). Discovering level of participation in MOOCs through clusters analysis. In 16th International Conference on Advanced Learning Technologies (ICALT), (pp. 232-233). IEEE. https://doi.org/10.1109/ICALT.2016.45

Rourke, L., Anderson, T., Garrison, D. R., \& Archer, W. (2001). Assessing social presence in asynchronous text-based computer conferencing. Journal of Distance Education, 14(2), 51-70.

Rovai, A. (2002). Building sense of community at a distance, The International Review of Research in Open and Distributed Learning, 3(1), 1-16. http://doi.org/10.19173/irrodl.v3i1.79

Rovai, A., \& Barnum, K. T. (2007). On-line course effectiveness: An analysis of student interactions and perceptions of learning. International Journal of E- Learning \& Distance Education, 18(1), 57-73. Retrieved from http://www.ijede.ca/index.php/jde/article/view/121

Shah, D. (2015, December 21). By the numbers: MOOCs in 2015. [Web log post]. Retrieved from https://www.class-central.com/report/moocs-2015-stats/

Short, J., Williams, E., \& Christie, B. (1976). The social psychology of telecommunications. London, New York: Wiley.

Swan, K. (2002). Building learning communities in online courses: The importance of interaction. Education, Communication \& Information, 2(1), 23-49.

Swan, K. (2003). Developing social presence in online course discussions. Learning and Teaching with Technology: Principles and Practices, 147-164.

Swan, K. (2004). Relationships Between Interactions and Learning in Online Environments. [Report]. The Sloan Consortium. Retrieved from http://moodle.isle.ac.nz/pluginfile.php/2782/mod data/content/19/Learning\%20in\%20online\%20environments.pdf

Swan, K., Shea, P., Richardson, J., Ice, P., Garrison, D. R., Cleveland-Innes, M., \& Arbaugh, J. B. (2008). Validating a measurement tool of presence in online communities of inquiry. E-Mentor, 2(24), 1-12. 
Tao, Y. (2009). The relationship between motivation and online social presence in an online class. (Doctoral dissertation). Available on ProQuest. Retrieved from http://stars.library.ucf.edu/etd/3871/

Thomas, S. (2000). Ties that bind: A social network approach to understanding student integration and persistence. Journal of Higher Education, 591-615.

http://doi.org/10.1080/o0221546.2000.11778854

Tu, C.-H. (2002). The Measurement of Social Presence in an Online Learning Environment. International Journal on E-Learning, 1(2), 34-45.

Tu, C.-H., \& McIsaac, M. (2002). The relationship of social presence and interaction in online classes. The American Journal of Distance Education, 16(3), 131-150.

http://doi.org/10.1207/S15389286AJDE1603_2

Weaver, C. M., \& Albion, P. (2005). Momentum in online discussions: The effect of social presence on motivation for participation. In H. Goss (Ed.), Proceedings ASCILITE 2005: 22nd Annual Conference of the Australasian Society for Computers in Learning in Tertiary Education: Balance, Fidelity, Mobility-Maintaining the Momentum? (pp. 703-706). Brisbane, Qld.: Queensland University of Technology, Dept. of Teaching and Learning Support Services

Webb, N. M. (1982). Student interaction and learning in small groups. Review of Educational Research, 52(3), 421-445. https://doi.org/10.3102/00346543052003421

Weidlich, J., \& Bastiaens, T. J. (2017). Explaining social presence and the quality of online learning with the SIPS model. Computers in Human Behavior, 72, 479-487.

http://doi.org/10.1016/j.chb.2017.03.016

Yang, D., Sinha, T., Adamson, D., \& Rosé, C. P. (2013). Turn on, tune in, drop out: Anticipating student dropouts in massive open online courses. In Proceedings of the 2013 NIPS data-driven education workshop (Vol. 11, p. 14). Retrieved from http://lytics.stanford.edu/datadriveneducation/papers/yangetal.pdf

\section{Athabasca \\ University}

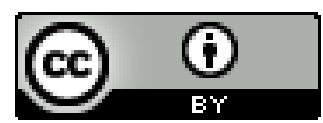

